\title{
Study on Supply Chain considering Anticipated Regret under Price Discount
}

\author{
Nian Zhang (iD) and Bin Li \\ School of Economics and Management, Chongqing University of Posts and Telecommunications, Chongqing 400065, China \\ Correspondence should be addressed to Nian Zhang; chinazhangnian@163.com
}

Received 13 July 2020; Revised 22 September 2020; Accepted 23 September 2020; Published 12 October 2020

Academic Editor: Dimitri Volchenkov

Copyright ( 2020 Nian Zhang and Bin Li. This is an open access article distributed under the Creative Commons Attribution License, which permits unrestricted use, distribution, and reproduction in any medium, provided the original work is properly cited.

\begin{abstract}
The aim of this study is to research the impact of consumer regrets on the supply chain caused by the company's "discount promotion." This paper introduces the theory of anticipated regret and price discount into the supply chain. By quoting the negative utility formula of consumers' anticipated regret under price discount, it quantitatively describes the demand function of the original product and the discount product. The model under centralized and decentralized decision making is constructed, and revenue-sharing contract is adopted to coordinate the supply chain. The conclusions are as follows. (1) Affected by the anticipated regret under the price discount, the price of the product increases first and then decreases with the regret sensitivity coefficient and consumer heterogeneity sensitivity increases. In addition, the price under the leadership structure of the manufacturer is the highest. (2) Price discounts enhance consumers' perception of anticipated regret. Under the stimulation of price discounts, the price of products increases first and then decreases. (3) The revenue-sharing contract could not coordinate the supply chain, and the introduction of a profit-sharing mechanism is achieved the Pareto improvement of the supply chain.
\end{abstract}

\section{Introduction}

The COVID-19 (coronavirus disease 2019) outbreak at the end of 2019 has directly hit the world economy [1]. In order to take relevant prevention and control measures, many stores have been closed, which will inevitably cause economic depression. Recently, the COVID-19 epidemic has been under control in China, and retail enterprises have also begun to open and adopted marketing strategies such as promotion coupons or discount vouchers to attract consumers. For example, clothing vendors usually use different discount promotions in shopping malls, such as $20 \%$ off for two Nike clothes discount, $500 \mathrm{RMB}$ off if you purchase the cloth of China Li-Ning over 1299 RMB, and 50\% off for GXG annual discount. In the nonepidemic period, price discount promotion is also a preferred marketing strategy for many retail enterprises, such as TMALL's "Double 11," Amazon Black Friday, JingDong's "618," and so on. Although the price discount has expanded the sales volume to some extent, it may also cause consumers' regret of shopping. Under the stimulation of price discount, consumers tend to expect the value of current original price products and the future discount products, respectively. When they realize that they may regret their current choice in the future, the negative emotions displayed are anticipated regret [2]. For example, during the epidemic period, many clothing retailers implement price discount promotion for stock products in Alibaba while optimizing inventory and product availability. Although the price of this part of goods is much lower than before, the style of those may be outdated or unpopular, and consumers would often regret their purchasing behavior. There are a lot of returns after shopping festivals. We all know that returning a product can take a lot of time and energy. However, the operations and logistics people surely felt the burden and the cost of receiving high volumes of returns.

On the one hand, due to the universal existence of consumers' anticipated regret, the related problems have aroused sufficient attention in the academic circle. In recent years, many scholars have studied how consumers' 
anticipated regret affects the supply chain. On the other hand, due to the serious loss in the return and exchange of products, members of the supply chain only consider their benefits and do not care about the decision making of other members, which seriously affect the supply chain product circulation. The specific performance is as follows: the profit of the supply chain and members is not guaranteed, the supply chain system is not coordinated, etc. Therefore, how to coordinate and realize the win-win of supply chain node enterprises has become a classic topic of supply chain management.

This paper considers the consumer's anticipated regret under the price discount, deduces the demand function of the original product and discounted product, and builds a supply chain game model. The relationship between regret sensitivity coefficient, consumer heterogeneity and equilibrium price, product demand, and corporate member profit is analyzed. The consumer purchase behavior is analyzed through the practical problems of "discount strategy," which enriches the supply chain management theory and provides a reference for the market under the price discount.

\section{Literature Review}

The relevant research of this paper involves consumers' anticipated regret caused by price discount and enterprises' pricing decision on the supply chain. To study these problems, we need to study from the pricing decision and coordination of the supply chain related to price discount and anticipated regret. Raju [3] first found that the increase in discount range would increase the variability of category sales, while the increase in discount frequency would have the opposite effect. Xia [4] solved the problem of how the retailer used ordering and pricing decision to respond to supplier's temporary price discount. Cai et al. [5] analyzed three models: supplier Stackelberg, retailer Stackelberg, and Nash game, and found that considering price discount not only could bring more profits but also reduced channel conflicts in the supply chain. Andrews et al.'s [6] empirical research showed that "discount promotion" could significantly promote consumption, and price discount should be moderate rather than excessive. Gao et al. [7] studied the dual-channel supply chain under the price discount and found that price discount in the online retail market would amplify the bullwhip effect of the supply chain. Chen et al. [8] analyzed and compared the traditional retail channel and online channel supply chain under the condition of price discount and found that the retailer discount level under the condition of the online channel is positively correlated with the manufacturer's cost input and promotional enthusiasm. By comparing and analyzing the dynamic pricing strategy and price commitment strategy, Li and Puyang [9] found that the price commitment strategy was the best in the case of online shopping and obtained the best discount level of online retailers. Wei and Xiong [10] studied the influence of various market factors, such as promotion, price and shelf display volume on the decision making, and profit of supply chain members under the revenue-sharing contract environment of the two-echelon supply chain. Wang et al. [11] discussed consumers' preference for participative products at different discount levels, and the results showed that moderate discount could improve the identification of customers and companies, while substantial discount could reduce the identification of customers and reduce consumers' preference for participative products. Yang and Liu [12] studied the difference of pricing strategies and extremely expected earnings of sellers under three different discount levels. The above research study found that price discount had an impact on consumers' purchasing decisions, corporate profits, and product supply chain. However, most of the existing studies on price discount assume that consumers are perfectly rational. In the actual purchase process, consumers are extremely vulnerable to the induction of price discount and may have regret emotions when making purchase decisions.

The regret theory was first proposed by Loomes and Sugden [13]. In recent years, some scholars have conducted modeling research on the supply chain considering the consumers' expectations in the later period from different perspectives. For example, Nasiry and Popescu [14] analyzed and compared the influence of "action regret" and "give up regret" on consumers' purchasing decisions in advance, providing a basis for enterprises to make sales strategies. Jiang et al. [15] studied the consumer utility formulas with these two kinds of regret and then analyzed the impact of anticipated regret on new product development of enterprises. Liu and Zhang [16] found that consumers' anticipated regret had both positive and negative impacts on corporate profits. The above literature mainly analyzes the impact of anticipated regret on consumer purchase and enterprise pricing. On this basis, this paper emphatically considers the impact of anticipated regret behavior caused by the discount strategy on supply chain member enterprises. At present, a part of the literature has begun to consider the influence of anticipated regret on the decision making of supply chain members. For example, Nie and Ding [17] established three leadership models of duopoly leader, traditional service provider leader, and emerging service provider leader and found that traditional service providers have "first-mover advantage" when product differentiation was relatively small. Gao et al. [18] analyzed the influence of anticipated regret on competitive remanufacturers and found that the profit of remanufacturers was positively correlated with anticipated regret. Since then, Gao et al. [19] established the supply chain model under the three operation modes of complete competition, integration, and channel cooperation and discussed how the choice of the operation mode of the remanufacturing supply chain was affected by the consumers' anticipated regret psychology. They found that the demand for remanufacturing products and the profit of remanufacturing products under the three modes were positively related to the consumers' anticipated regret sensitivity, and the demand for new products was negatively related to the consumers' anticipated regret sensitivity. Khan et al. [20] conducted their study by collecting data via an online survey and found that consumers' economic animosity increases their anticipated regret towards purchasing a foreign product originating from a target 
market of animosity. Zou et al. [21] studied the design of product lines in view of consumers' anticipated regret behavior, and the results show that when the anticipated regret behavior of consumers is stronger, enterprises should enlarge the quality difference of product line.

The above research study shows that anticipated regret has a significant effect on the decision making of supply chain members, but it does not study the impact of anticipated regret caused by "price discount" on supply chain members. The "price discount strategy" has become the most commonly used means of promotion for enterprises, which not only brings about a surge in transaction volume for enterprises but also makes consumers face the shopping problem of product shortage and code interruption during the promotion period. Consumers need to make a purchase choice before they know the uncertain promotion environment in the future or the real value brought by the original price products and discount products. Once the uncertainty disappears and the real value is determined, consumers will regret when they know that they could have made a better choice. Along with the frequent price promotion strategy, consumers' regret expectation will be more common, which will greatly affect the promotion decision of enterprises and make the supply chain evolve new characteristics and laws.

This paper aims at the discount promotion strategy of enterprises, considers the consumer's anticipated regret under the price discount, deduces the demand function of the original price product and discounted product, and builds a supply chain game model. The relationship between regret sensitivity coefficient, consumer heterogeneity and equilibrium price, product demand, and corporate member profit is analyzed. The consumer purchase behavior is analyzed through the practical problems of "discount promotion," which enriches the supply chain management theory and provides a reference for the marketing practice under the corporate price discount strategy.

\section{Problem Description and Assumptions}

Enterprises often use the means of "discount promotion" to attract customers. At present, many merchants have announced the future price discount of products before the "Double 11" Carnival, which enables consumers to know the discount information in advance and further increases the regret emotion of consumers in the purchase decision process of original price products and discount products. For example, in early October, consumer A was interested in a down jacket that had just come into the market at the original price. Based on past shopping experience, he learned that he could buy this down jacket at a $20 \%$ discount in the future. At this time, consumer A is faced with two choices: if he buys the down jacket at the current price, he may regret that he bought it too expensive; if he buys the down jacket at the future discount, he may regret that he missed the purchase opportunity due to uncertain factors such as out of order. This kind of consumer anticipates the future risk before the decision performance is the anticipated regret. In the model constructed in this paper, the specific parameter symbol definitions and assumptions are shown in Table 1.

We consider a supply chain consisting of a manufacturer (denoted by subscript $m$ ) and a retailer (denoted by subscript $r$ ). The original price products in the market will be sold at a discount at a certain point in the future, where the retailer adopts the price commitment strategy, that is, the discount coefficient is known in advance, so $p_{d}=\delta p_{n}$ ( $p_{d}$ is the unit retail price of the discount products, $\delta$ is the unit product discount level, and $p_{n}$ is the unit retail price of the original products). According to the degree of consumer preference for discount products, it is divided into two types: high preference type $\theta_{H}$ type consumers have a higher preference for discount products) and low preference type $\left(\theta_{L}\right.$ type consumers have a lower preference for discount products). $\theta_{H}$ and $\theta_{L}$, respectively, represent the ratio of the valuation of discounted products of these two types of consumers to the valuation of original price products. This article draws on the literature of Gao et al. [18] and Liu and Zhang [16], assuming $\theta_{H}=1$ and $\theta_{L}=1-\gamma$.

Let $x$ denote the portion of high preference customers and $1-x$ denote low preference ones; then, expected utility of consumers could be $\left(x \theta_{H}+(1-x) \theta_{L}\right) v$. In this paper, we assumed that $x$ follows uniform distribution on the interval $[0,1]$, which is characterized by the property of choosing the original price product or the discount product. Then, the expected utility of consumers purchasing discount products can be expressed as $\left(\theta_{H}+\theta_{L} / 2\right) v$, where $v$ is the utility of purchasing the product at the original price. Since consumers have a certain fear of regret, the regret generated before the purchase decision will have a certain negative effect. This article refers to the research of Nasiry and Popescu [14] to express the negative effect of regret as follows:

$$
\text { A.R. }=-\lambda_{i} \times \operatorname{prob}\left(U_{f}>U_{c}\right) \times\left(U_{f}-U_{c}\right),
$$

where $U_{f}$ represents the net utility generated by abandoning the purchase of the original price product or discount product, $U_{c}$ represents the net utility generated by choosing to purchase the original price product or discount product, and $\lambda_{i}(i \in\{f, c\})$ represents the regret sensitivity coefficient of consumers. If a consumer chooses to purchase the original price product, he or she may regret it later (that is, the actual $\theta_{H}$-type consumer regrets), and the net effect of giving up the purchase of the original price products (that is, the purchase of discount products) is $U_{f}=v-p_{n}$, and the actual net utility of purchasing the original price products is $U_{c}=\theta_{L} v-p_{d}=(1-\gamma) v-\delta p_{n}$. Similarly, if a consumer chooses to purchase the discount product, he or she may regret it later (that is, the actual $\theta_{L}$-type consumer regrets), and the net effect of giving up the purchase of the discount product (that is, the purchase of original price products) is $U_{f}=v-p_{n}$, and the actual net utility of purchasing the discount product is $U_{c}=\theta_{L} v-p_{d}=(1-\gamma) v-\delta p_{n}$. The consumer's net utility function is shown in Table 2 . Therefore, the net utility functions of consumers' regret for purchasing original price products and discount products are as follows: 
TABLe 1: Explanation of main symbols and hypothesis.

\begin{tabular}{|c|c|c|}
\hline Variable symbol & Variable description & Parameter range and assumptions \\
\hline$p_{n}$ & Unit retail price of the original products & \\
\hline$p_{d}$ & Unit retail price of the discount products & \\
\hline$\delta$ & Unit product discount level & \\
\hline$w$ & Unit wholesale price of products & $\lambda_{c}=\lambda_{f}=\lambda$ \\
\hline$\theta_{H}$ & Consumers with a higher preference for discount products & $\theta_{H}=1$ \\
\hline$\theta_{L}$ & Consumers with low preference for discount products & $\theta_{L}=1-\gamma \operatorname{prob}\left(U_{f}>U_{c}\right)=(1 / 2)$ \\
\hline$\gamma$ & $\begin{array}{l}\text { Consumer heterogeneity, which means the difference between the acceptance of } \\
\text { discount products by } \theta_{H} \text {-type consumers and } \theta_{L} \text {-type consumers, } \gamma=\theta_{H}-\theta_{L}\end{array}$ & $\begin{aligned} \theta_{L}<\theta_{H} \\
0<\lambda<1\end{aligned}$ \\
\hline & The effectiveness of consumers buying products at original prices, $v \in[0,1]$, subject & \\
\hline$v$ & to unifor & \\
\hline$U_{f}$ & Net utility resulting from abandonment of purchase & \\
\hline & Net utility resulting from choosing to purchase & \\
\hline $\operatorname{prob}\left(U_{f}>U_{c}\right)$ & The possibility of regret & \\
\hline$\lambda_{i}(i \in\{f, c\})$ & Regret sensitivity coefficient, which is used to measure consumers' sensi & itivity to anticipated regret \\
\hline
\end{tabular}

TABLE 2: Consumer's net utility function.

\begin{tabular}{lcc}
\hline Consumers' buying propensity & $\begin{array}{c}\text { Net utility resulting from abandonment of } \\
\text { purchase }\end{array}$ & $\begin{array}{c}\text { Net utility resulting from choosing to } \\
\text { purchase }\end{array}$ \\
\hline $\begin{array}{l}\theta_{H} \text { type (abandon original price products and } \\
\text { purchase discount products) }\end{array}$ & $U_{f}=\theta_{H} v-p_{d}=v-\delta p_{n}$ & $U_{c}=v-p_{n}$ \\
\hline $\begin{array}{l}\theta_{L} \text { type (abandon discount products and purchase } \\
\text { original price products) }\end{array}$ & $U_{f}=v-p_{n}$ & $U_{c}=\theta_{L} v-p_{d}=(1-\gamma) v-\delta p_{n}$ \\
\hline
\end{tabular}

$$
\begin{aligned}
U_{n}= & \nu-p_{n}-\frac{\lambda}{2}\left(\left(\nu-\delta p_{n}\right)-\left(\nu-p_{n}\right)\right) \\
= & \nu+\frac{p_{n}}{2}(-2+(\delta-1) \lambda), \\
U_{d}= & \frac{\left(v-\delta p_{n}\right)+\left((1-\gamma) v-\delta p_{n}\right)}{2} \\
& -\frac{\lambda}{2}\left(\nu-p_{n}-\left((1-\gamma) \nu-\delta p_{n}\right)\right) \\
= & \frac{v}{2}(2-\gamma-\lambda \gamma)+\frac{p_{n}}{2}(\lambda-2 \delta-\lambda \delta) .
\end{aligned}
$$

Similar to the description of Örsdemir et al. [22], consumers purchase original price products when $U_{n}>U_{d}$ and $U_{n}>0$ are satisfied; consumers purchase discount products when $U_{n}<U_{d}$ and $U_{d}>0$ are satisfied. Therefore, consumers' demand functions for original price products and discount products are as follows:

$$
\begin{aligned}
& D_{n}=\int_{U_{n}>U_{d}} f(v) \mathrm{d} v= \begin{cases}1-\frac{p_{n}(2+\lambda-\delta \lambda)}{2}, & \text { if } p_{n} \leq 0, \\
1+\frac{2 p_{n}(\delta-1)}{\gamma}, & \text { if } 0 \leq p_{n} \leq \frac{\gamma}{2-2 \delta}, \\
0, & \text { if } p_{n} \geq \frac{\gamma}{2-2 \delta},\end{cases} \\
& D_{d}=\int_{U_{d}>U_{n}} f(v) \mathrm{d} v= \begin{cases}0, & \text { if } p_{n} \leq 0, \\
-\frac{2 p_{n}(\delta-1)}{\gamma}-\frac{p_{n}(\lambda-\delta(2+\lambda))}{-2+\gamma+\gamma \lambda}, & \text { if } 0 \leq p_{n} \leq \frac{\gamma}{2-2 \delta}, \\
1-\frac{p_{n}(\lambda-\delta(2+\lambda))}{-2+\gamma+\gamma \lambda}, & \text { if } p_{n} \geq \frac{\gamma}{2-2 \delta} .\end{cases}
\end{aligned}
$$


In the game model, when $0 \leq p_{n} \leq(\gamma / 2-2 \delta)$, consumers would purchase both original price products and discount products. When $p_{n} \geq(\gamma / 2-2 \delta)$, consumers just purchase discount products and would not purchase original price products. In this paper, to research consumers' anticipated regret under the price discount and make sure there are two products on the market, we only consider $0 \leq p_{n} \leq(\gamma / 2-2 \delta)$. In order to ensure that the supply chain enterprises are profitable, the retail price of products needs to satisfy the inequality $0 \leq p_{n} \leq(\gamma / 2-2 \delta)$, and the demand functions of the original price products and the discount products are as follows:

$$
\begin{aligned}
& D_{n}=1+2 p_{n} A, \\
& D_{d}=(-2 A-B) p_{n},
\end{aligned}
$$

where $A=(\delta-1 / \gamma)$ and $B=(\lambda-\delta(2+\lambda) / \gamma+\gamma \lambda-2)$.

\section{Supply Chain Decision-Making Model}

In the supply chain decision making with nonleadership power structure, the manufacturer sets the wholesale price of products and the retailer sets the retail price of products. According to the demand functions of the original price products and discount products, the profit functions of the manufacturer and the retailer can be obtained as follows:

$$
\pi_{m}(w)=(w-c)\left(1+2 p_{n} A\right)+(w-c)\left(-2 p_{n} A-p_{n} B\right),
$$

$$
\pi_{r}\left(p_{n}\right)=\left(p_{n}-w\right)\left(1+2 p_{n} A\right)+\left(\delta p_{n}-w\right)\left(-2 p_{n} A-p_{n} B\right) .
$$

4.1. Centralized Decision Making. In the case of centralized decision making $(\mathrm{CL})$, the manufacturer and the retailer form a unified decision-making leader to determine the optimal pricing strategy that maximizes the overall profit of the supply chain. From the above analysis, we can obtain the profit of the supply chain $\pi^{\mathrm{CL}}$ as follows:

$$
\begin{aligned}
\pi^{\mathrm{CL}}= & (w-c)\left(1-p_{n} B\right)+\left(p_{n}-w\right)\left(1+2 p_{n} A\right) \\
& +\left(\delta p_{n}-w\right)\left(-2 p_{n} A-p_{n} B\right) .
\end{aligned}
$$

Since $\pi^{\mathrm{CL}}>0$ needs to be satisfied, $8 A(-1+\delta)+4 B \delta>0$ and $\left(\partial^{2} \pi^{\mathrm{CL}} / \partial p_{n}^{2}\right)=4 A-4 A \delta-2 B \delta<0$ are satisfied. So, the stagnation point is the point where the profit of the unconstrained equilibrium model is maximized. Derive $p_{n}$ in equation (7), and the equilibrium expression of retail price $p_{n}$ is as follows:

$$
p_{n}^{\mathrm{CL} *}=\frac{1+B c}{-4 A+4 A \delta+2 B \delta} .
$$

Substituting the above expression into equation (7), the optimal profit of the supply chain is as follows:

$$
\pi^{\mathrm{CL} *}=\frac{(1+B c)^{2}}{8 A(-1+\delta)+4 B \delta}-c .
$$

4.2. Decentralized Decision Making. In decentralized decision making (DL), the manufacturer and the retailer, respectively, set the wholesale price and retail price to maximize their own benefits and are not leaders. Since $A<0$, $B>0$, and $p_{n}=w+b$ ( $b$ is the unit profit of the retailer), $\pi_{m}(w)$ is available. Therefore, $\left(\partial^{2} \pi_{m} / \partial w^{2}\right)=-2 B<0$ and $\left(\partial^{2} \pi_{r} / \partial p_{n}^{2}\right)=4 A(1-\delta)-2 B \delta<0$, and the stagnation point is the point where the profit of the unconstrained equilibrium model is maximized. Taking the partial derivative of $w$ and $p_{n}$ in the equations (5) and (6), the expression of unconstrained equilibrium $w$ and $p_{n}$ is obtained as follows:

$$
\begin{aligned}
w^{\mathrm{DL} *} & =\frac{1}{B}+c-\frac{2+B c}{B(1+2 \delta)+4 A(\delta-1)}, \\
p_{n}^{\mathrm{DL} *} & =\frac{2+B c}{B(1+2 \delta)+4 A(\delta-1)} .
\end{aligned}
$$

The optimal demand for the original price products and discount products and the optimal profits of the manufacturer and the retailer are as follows:

$$
\begin{aligned}
D_{n}^{\mathrm{DL} *} & =1+\frac{2 A(2+B c)}{B(1+2 \delta)+4 A(\delta-1)}, \\
D_{d}^{\mathrm{DL} *} & =-\frac{(2+B c)(2 A+B)}{B(1+2 \delta)+4 A(\delta-1)}, \\
\pi_{m}^{\mathrm{DL} *} & =\frac{\left(4 A+B+B^{2} c-2(2 A+B) \delta\right)^{2}}{B(B(1+2 \delta)+4 A(\delta-1))^{2}}, \\
\pi_{r}^{\mathrm{DL} *} & =\frac{1}{2}\left(\begin{array}{c}
\frac{(2+B c)(4+B c)}{B(1+2 \delta)+4 A(\delta-1)}- \\
\frac{B(2+B c)^{2}}{(B(1+2 \delta)+4 A(\delta-1))^{2}}-\frac{2}{B}-2 c
\end{array}\right) .
\end{aligned}
$$

\section{Model Comparison and Analysis}

This section compares and analyzes the supply chain model in detail.

Proposition 1. (1) When $\gamma<(2-2 \delta / 1+\delta)$, $p_{n}^{D L *}$ is positively correlated with $\lambda, D_{d}^{D L *}$ is positively correlated with $\lambda$, and $D_{n}^{D L *}$ is negatively correlated with $\lambda$. (2) When $(2-2 \delta / 1+\delta)<\gamma, p_{n}^{D L *}$ is negatively correlated with $\lambda, D_{d}^{D L *}$ is negatively correlated with $\lambda$, and $D_{n}^{D L *}$ is positively correlated with $\lambda$.

Proposition 1 shows that when the consumer heterogeneity is lower, as the sensitivity of regret increases, the retail price of the original price products would rise, the demand of the original price products would decrease, and the demand of discount products would increase. This is because the original price product has a "price advantage" when the discount is large. However, when the consumer heterogeneity is higher, the retail price of the original price product gradually decreases, and then the demand of the original price product increases, and the demand of discount products decreases. This is because consumers' anticipated 
regret of the product would generate a higher degree of fear and reduce the consumers' expected utility when the discount is small. In order to avoid this risk, companies adopt "penetration pricing strategy" or "discount promotion" to stimulate market demand.
Proof. When $\gamma>(2-2 \delta / 1+\delta)$ and $-2+\gamma+(2+\gamma) \delta>0$, the expressions of $p_{n}^{\mathrm{DL} *}, D_{n}^{\mathrm{DL} *}$, and $D_{d}^{\mathrm{DL} *}$, respectively, are used to find the first-order partial derivative of $\lambda$ and obtain the following:

$$
\begin{aligned}
& \frac{\partial p_{n}^{\mathrm{DL} *}}{\partial \lambda}=\frac{2 \gamma\left(\gamma-2 c(1-\delta)^{2}+2 \gamma \delta\right)(2-\gamma-(2+\gamma) \delta)}{\left(-8(-1+\delta)^{2}+r(4+5 \lambda+\delta(-10+(-7+2 \delta) \lambda))\right)^{2}}<0, \\
& \frac{\partial D_{n}^{\mathrm{DL} *}}{\partial \lambda}=\frac{4(1-\delta)(2-\gamma-(2+\gamma) \delta)\left(2 c(1-\delta)^{2}-\gamma(1+2 \delta)\right)}{\left(\gamma(4+5 \lambda-\delta(10+(7-2 \delta) \lambda))-8(1-\delta)^{2}\right)^{2}}>0, \\
& \frac{\partial D_{d}^{\mathrm{DL} *}}{\partial \lambda}=\frac{\left((2-\gamma-(2+\gamma) \delta)\left(\boldsymbol{c}\left(\begin{array}{c}
\gamma^{2}\left(4 \delta(2+3 \delta)-4\left(2-\delta-\delta^{2}\right) \lambda+(1-\delta)^{2}(1+2 \delta) \lambda^{2}-8\right) \\
c(2-\gamma-\gamma \lambda)^{2}+ \\
-16(1-\delta)^{2}(\gamma(2+(1-\delta) \lambda)+2(1-\delta))
\end{array}\right)\right)\right.}{(2-\gamma-\gamma \lambda)^{2}\left(\gamma(4+5 \lambda-\delta((7-2 \delta) \lambda+10))-8(1-\delta)^{2}\right)^{2}}<0 .
\end{aligned}
$$

Similarly, when $\gamma<(2-2 \delta / 1+\delta),-2+\gamma+(2+\gamma) \delta<0$, and then $\left(\partial p_{n}^{\mathrm{DL} *} / \partial \lambda\right)>0,\left(\partial D_{n}^{\mathrm{DL} *} / \partial \lambda\right)<0$, and $\left(\partial D_{d}^{D L *} /\right.$ $\partial \lambda)>0$ can be obtained. Therefore, Proposition 1 is proved.

Proposition 2. (1) When $\gamma^{D L *}<A_{1}, p_{n}^{D L *}$ is positively correlated with $\gamma$; when $\gamma^{D L *}>A_{1}, p_{n}^{D L *}$ is negatively correlated with $\gamma$. (2) $D_{n}^{D L *}$ is positively correlated with $\gamma$, and $D_{d}^{D L *}$ is negatively correlated with $\gamma$. Let $A_{1}=\left(4(\delta-1)^{2}\right)$ / $\left((2+2 \lambda)(\delta-1)^{2}+\sqrt{(\delta-1)^{2}(1+2 \delta)(1+\lambda)(\delta(2+\lambda)-\lambda)}\right)$.

Proposition 2 shows that retail prices would increase first and then decrease as consumer heterogeneity increases. This indicates that in the case of lower consumer heterogeneity, the original price product is more attractive, so the demand of the original price product increases and the demand of discounted products decreases, which in turn increases the price of the original price product. When consumer heterogeneity is high, companies adopt the "penetrating pricing" strategy to attract high-preferred consumers and stimulate the increase in sales, which also prompts some consumers who prefer discount products to purchase original products.

Proof. In decentralized decision making, the retail price expression $p_{n}^{\mathrm{DL} *}$ is used to find the first-order partial derivative of $\gamma$ and obtain the following:

$$
\frac{\partial p_{n}^{\mathrm{DL} *}}{\partial \gamma}=\frac{2\left(4(1-\delta)^{2}(4+2 c \delta-c(1-\delta) \lambda)-16 \gamma(1-\delta)^{2}(1+\lambda)+\gamma^{2}(1+\lambda)(4+5 \lambda-\delta(10+(7-2 \delta) \lambda))\right)}{\left(\gamma(4+5 \lambda-\delta(10-(7-2 \delta) \lambda))-8(1-\delta)^{2}\right)^{2}}
$$

When $\gamma^{\mathrm{DL} *}<A_{1}$, there is $\left(\partial p_{n}^{\mathrm{DL} *} / \partial \gamma\right)>0$. When $\gamma^{\mathrm{DL} *}>A_{1}$, there is $\left(\partial p_{n}^{\mathrm{DL} *} / \partial \gamma\right)<0$.
Since $\pi_{m}^{\mathrm{DL} *}>0$ must be satisfied, $\delta(2+\lambda)-\lambda>0$ can be obtained, and the required expressions $D_{n}^{\mathrm{DL} *}$ and $D_{d}^{\mathrm{DL} *}$ are 
first-order partial derivatives of $\gamma$, and we can obtain the following:

$$
\begin{aligned}
\frac{\partial D_{n}^{\mathrm{DL} *}}{\partial \gamma}= & \frac{2(1-\delta)(\lambda-\delta(2+\lambda))(c(4+5 \lambda-\delta(10(7-2 \delta) \lambda))-4-8 \delta)}{\left(\gamma(4+5 \lambda-\delta(10(7-2 \delta) \lambda))-8(1-\delta)^{2}\right)^{2}}>0, \\
& (2-\gamma-\lambda)(\gamma(2+\lambda-\delta \lambda)-4(1-\delta))(4+5 \lambda-\delta(10+(7-2 \delta) \lambda))(2 \gamma(1+\lambda)+c(\lambda-\delta(2+\lambda))-4) \\
& -2(1+\lambda)(2-\gamma-\gamma \lambda)(\gamma(2+\lambda-\delta \lambda))\left(\begin{array}{c}
\gamma(4+5 \lambda-\delta(10+(7-2 \delta) \lambda))- \\
4(1-\delta)-8(1-\delta)^{2}
\end{array}\right) \\
& -(2-\gamma-\gamma \lambda)(2+\lambda-\delta \lambda)(2 \gamma(1+\lambda)+c(\lambda-\delta(2+\lambda))-4)\left(\begin{array}{c}
\gamma\left(\begin{array}{c}
4+5 \lambda- \\
\delta(10+(7-2 \delta) \lambda)
\end{array}\right)-8(-1+\delta)^{2}
\end{array}\right) \\
\frac{\partial D_{d}^{\mathrm{DL} *}}{\partial \gamma}= & \frac{-(1+\lambda)(4(1-\delta)+\lambda(2+\lambda-\delta \lambda))\left(\begin{array}{c}
2 \gamma(1+\lambda)+ \\
c(\lambda-\delta(2+\lambda))-4
\end{array}\right)\left(\begin{array}{c}
4+5 \lambda- \\
\gamma(10+(7-2 \delta) \lambda)
\end{array}\right)-8(1-\delta)^{2}}{\delta(2-\gamma-\gamma \lambda)^{2}\left(\gamma(4+5 \lambda-\delta(10+(7-2 \delta) \lambda))-8(1-\delta)^{2}\right)^{2}}
\end{aligned}
$$

Therefore, Proposition 2 is proved.

Proposition 3. (1) When $\delta^{D L *}<A_{2}, p_{n}^{D L *}$ is positively correlated with $\delta$; when $\delta^{D L *}>A_{2}, p_{n}^{D L *}$ is negatively correlated with $\delta$. (2) When $\delta^{D L *}<A_{3}, D_{n}^{D L *}$ is negatively correlated with $\delta$; when $\delta^{D L *}<A_{3}, D_{n}^{d *}$ is positively correlated with $\delta$. (3) When $\delta^{D L *}<A_{4}, D_{d}^{D L *}$ is positively correlated with $\delta$; when $\delta^{D L *}>A_{4}, D_{d}^{D L *}$ is negatively correlated with $\delta$. Let $A_{2}=(-16+10 \gamma+7 \gamma \lambda /(4(-4+\gamma \lambda))), A_{3}=(1-$ $\sqrt{(3 \gamma / 4-\gamma \lambda)})$, and $A_{4}=\left(\left(16-8 \gamma(1+\lambda)+\gamma^{2} \lambda(2+\lambda)-\right.\right.$ $\left.\left.\sqrt{6} \sqrt{-\gamma(-4+\gamma \lambda)^{2}(-2+\gamma+\gamma \lambda)}\right) /(-4+\gamma \lambda)^{2}\right)$.
Proposition 3 shows that there would be a threshold value of the price discount coefficient for retail prices. When this threshold is exceeded, the retail price would decrease. At this time, as the utility of purchasing original price products improves, some consumers who prefer discount products shift their consumption intentions to original price products, resulting in a decline in demand of discount products and an increase in demand of original price products.

Proof. Under decentralized decision making, the expression for $p_{n}^{\mathrm{DL} *}$ can be used to find the first-order partial derivative of $\delta$ and obtain the following:

$$
\frac{\partial p_{n}^{\mathrm{DL} *}}{\delta}=\frac{2 \gamma\left((2-\gamma-\gamma \lambda)(2(8-5 \gamma-8 \delta)-(7-4 \delta) \gamma \lambda)+c\left(\begin{array}{c}
4\left(2-\gamma-2 \delta^{2}\right)- \\
2 \lambda(1-\delta)(2+\gamma-(2-\gamma) \delta)+\gamma(1-\delta)^{2} \lambda^{2}
\end{array}\right)\right)}{\left(\gamma(4+5 \lambda-\delta(10+(7-2 \delta) \lambda))-8(1-\delta)^{2}\right)^{2}}
$$

When $\delta^{\mathrm{DL} *}<A_{2}$, there are $4(1-\delta)+\gamma(-3-2 \lambda+\delta \lambda)>0$ and $\partial p_{n}^{\mathrm{DL} *} / \partial \delta<0$. When $\delta^{\mathrm{DL} *}>A_{2}$, there are $4(1-\delta)+$ $\gamma(-3-2 \lambda+\delta \lambda)<0$ and $\partial p_{n}^{\mathrm{DL} *} / \partial \delta<0$.

In the same way, the expressions of $D_{n}^{\mathrm{DL} *}$ and $D_{d}^{\mathrm{DL} *}$ can be proved by finding the first-order partial derivative of $\delta$, so Proposition 3 is proved.

\section{Revenue-Sharing Coordination}

In the decentralized decision making considering anticipated regret under price discount, each node enterprise always aims at its own interests, ignores the win-win cooperation between enterprises, and puts own profits first. This situation is likely to cause double marginal effects and cannot achieve interest objectives, and the efficiency of the supply chain is also affected, which is extremely detrimental to supply chain management. However, in reality, such an efficient mechanism of centralized decision making is not practical for independent companies because they cannot always make decisions as a community. Therefore, introducing a corresponding coordination mechanism on the basis of decentralized decision making has become a more effective method of enhancing channel competitiveness and strengthening long-term stable cooperation between enterprises in the supply chain. The revenue-sharing contract is adopted to coordinate the supply chain; in the early stages of the sale, the manufacturer sells wholesale products to the retailer at a low wholesale price $w$. After the sales cycle ends, the retailers receive $\varphi(0<\varphi<1)$ proportion of revenue and share $1-\varphi$ proportion of sales revenue to the manufacturers. On the basis of the above model, the profits of the manufacturer and retailer after the coordination of the revenue-sharing contract (the coordinated expression superscript is indicated by "CO") are, respectively, as follows: 


$$
\begin{aligned}
\pi_{m}^{\mathrm{CO}}(w)= & (w-c)\left(1-p_{n} B\right) \\
& +(1-\varphi)\left(p_{n}\left(1+2 p_{n} A\right)-\delta p_{n}\left((2 A+B) p_{n}\right)\right)
\end{aligned}
$$

$$
\begin{aligned}
\pi_{r}^{\mathrm{CO}}\left(p_{n}\right)= & \left(\varphi p_{n}-w\right)\left(1+2 p_{n} A\right) \\
& +\left(\varphi \delta p_{n}-w\right)\left((-2 A-B) p_{n}\right)
\end{aligned}
$$

The purpose of revenue-sharing contract is to make the optimal retail price under the nonleadership power structure be the same as the retail price when the expected profit of the supply chain is maximized, that is, $p_{n}^{\mathrm{CO}}=p_{n}^{\mathrm{CL}}$. The first-order derivative of the manufacturer's profit to $w$ and the retailer's profit to $p_{n}$ is calculated, respectively, as follows:

$$
\begin{aligned}
p_{n}^{\mathrm{CO}} & =\frac{2+B c}{B+4 A(\delta-1)+2 B \delta} \\
w^{\mathrm{CO}} & =\frac{(-B+2(1+B c)(2 A(\delta-1)+B \delta)) \varphi}{B(B+4 A(\delta-1)+2 B \delta)} .
\end{aligned}
$$

Taking $p_{n}^{\mathrm{CO}}$ back to equations (16) and (17), the profit functions of the manufacturer and retailer can be obtained.

An effective coordination mechanism should satisfy the following requirements:

$$
\begin{aligned}
& \pi_{m}^{\mathrm{CO}}\left(p_{n}^{\mathrm{CO}}, w^{\mathrm{CO}}, \varphi^{\mathrm{CO}}\right) \geq \pi_{m}^{\mathrm{DL}} \\
& \pi_{r}^{\mathrm{CO}}\left(p_{n}^{\mathrm{CO}}, w^{\mathrm{CO}}, \varphi^{\mathrm{CO}}\right) \geq \pi_{r}^{\mathrm{DL}}
\end{aligned}
$$

Comparing the equilibrium solution $p_{n}^{\mathrm{CO}}$ with $p_{n}^{\mathrm{CL}}$, when $\varphi \in[0,1]$ and $p_{n}^{\mathrm{CO}}<p_{n}^{\mathrm{CL}}$ are constant, the optimal retail price under decentralized decision making is always smaller than that under the supply chain's expected profit maximization. Therefore, the traditional revenue-sharing contract cannot coordinate the supply chain with nonleadership power structure effectively. The reason is that in the structure of no leadership, the manufacturer and the retailer determine their own wholesale price and retail price at the same time, and the manufacturer does not have an advantage in the pricing decision. After introducing revenuesharing contract, the retailer would obtain a lower wholesale price. The lower the wholesale price is, the lower the retail price is. Therefore, the overall profit of the supply chain after the revenue-sharing contract coordination is equal to that under decentralized decision making, so $\pi_{m}^{\mathrm{CO}}\left(p_{n}^{\mathrm{CO}}, w^{\mathrm{CO}}\right.$, $\left.\varphi^{\mathrm{CO}}\right) \geq \pi_{m}^{\mathrm{DL}}$ and $\pi_{r}^{\mathrm{CO}}\left(p_{n}^{\mathrm{CO}}, w^{\mathrm{CO}}, \varphi^{\mathrm{CO}}\right) \geq \pi_{r}^{\mathrm{DL}}$ cannot be satisfied at the same time.

In order to make up for the above revenue-sharing contract coordination failure, the manufacturer and the retailer would share the profits of the supply chain in the centralized decision-making process on the basis of decentralized decision making with nonleadership power structure and discuss the influence of different profit distribution parameters.

Therefore, the profit functions of the manufacturer and retailer are expressed as follows:

$$
\begin{aligned}
\pi_{m}^{\mathrm{CO}} & =\pi_{m}^{\mathrm{DL} *}+(1-\varphi) \Delta \pi, \\
\pi_{r}^{\mathrm{CO}} & =\pi_{r}^{\mathrm{DL} *}+\varphi \Delta \pi, \\
\Delta \pi & =\pi^{\mathrm{CL}}-\pi^{\mathrm{DL} *} .
\end{aligned}
$$

Therefore, $\quad \Delta \pi=\left(\left(4 A+B+B^{2} c-2(2 A+B) \delta\right)^{2} / 4(2 A\right.$ $\left.(\delta-1)+B \delta)(B+4 A(\delta-1)+2 B \delta)^{2}\right)$, where $\Delta \pi$ is the profit margin of the supply chain under centralized decision making and decentralized decision making. When the retailer's profit proportion $\varphi$ is larger, the retailer's profit is higher and the manufacturer's profit is lower. On the contrary, when the retailer's profit proportion $\varphi$ is smaller, the manufacturer's profit is higher and the retailer's profit is lower. When $\varphi=1$, the retailer takes the dominant position in the game, and he would get all the increased profit of the supply chain; when $\varphi=0$, on the contrary, the manufacturer takes the dominant position in the game, and he would get all the increased profit of the supply chain.

\section{Numerical Simulation}

On the basis of theoretical analysis, in order to further investigate intuitively, this part uses the numerical simulation method to research the impact of regret sensitivity coefficient and consumer heterogeneity on pricing decisions in the supply chain. According to the past experience, a down jacket will be on sale two months later, with a discount margin of $88 \%$. Suppose that the consumers who prefer discount down jackets are $\theta_{H}=1$ and the consumers who prefer original down jackets are $\theta_{L}=0.8$. Then, the consumer heterogeneity $\gamma=\theta_{H}=\theta_{L}=0.2$ indicates the difference between the two types of consumers' acceptance of discount down jackets, and the sensitivity of consumers to anticipated regret is $\lambda=0.3$. Therefore, the parameters of numerical simulation are set as $\delta=0.88, \gamma=0.2$, and $\lambda=0.3$.

7.1. Analysis of Anticipated Regret Sensitivity Coefficient. Because the anticipated regret behavior affects consumers' acceptance of the discounted down jacket products, an important impact on the sales volume, product production, and sales in the supply chain occurs. For further visual inspection, the change curves of wholesale price, retail price, and system profit in different leading markets are drawn when $\lambda \in[0,1]$, as shown in Figures 1 and 2 .

As can be seen from Figure 1, with the increase in regret sensitivity coefficient, the wholesale price and retail price of products will decrease. This shows that when consumers choose the existing original price down jacket and the future discount down jacket, they often have a fear psychology and expand the uncertainty of market transactions. Enterprises can adopt the "marking penetration pricing" strategy to stimulate market demand, which is used to attract customers to the original product by offering a lower price during its initial offering because lower price helps the original product penetrate the market and attract customers away from competitors. 


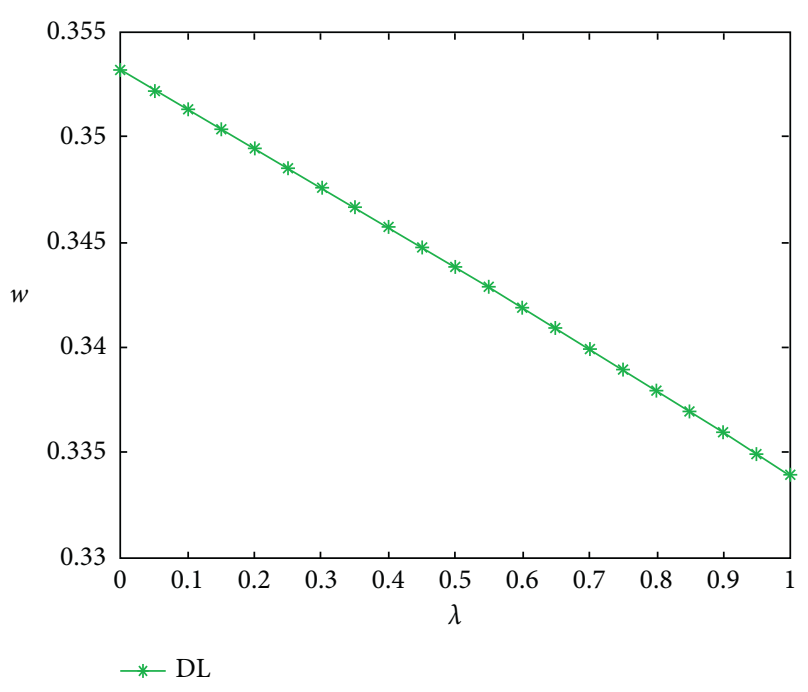

(a)

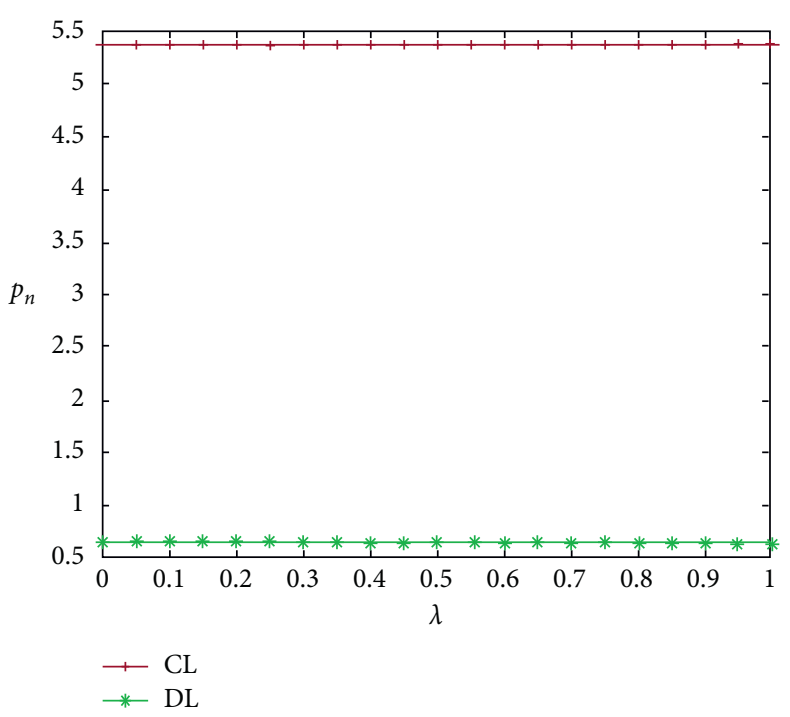

(b)

FIGURE 1: Effect of regret sensitivity coefficient on wholesale and retail prices.

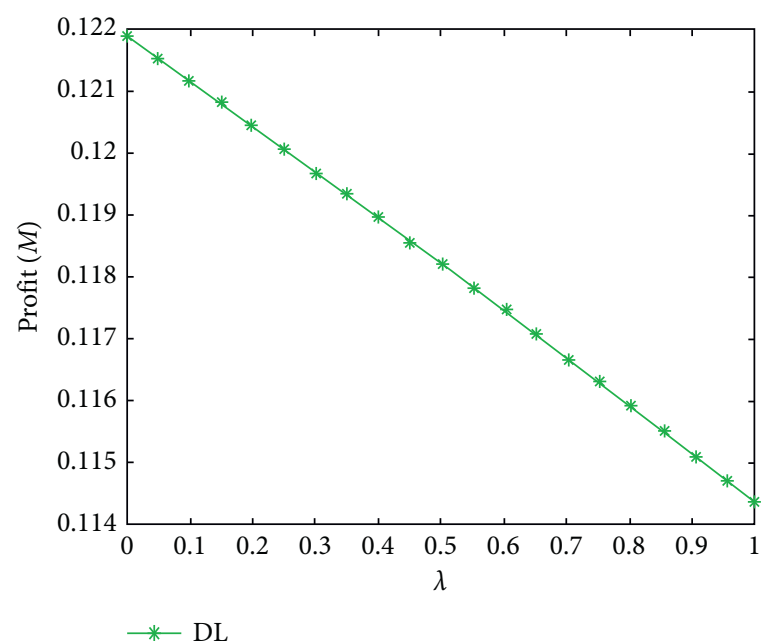

(a)

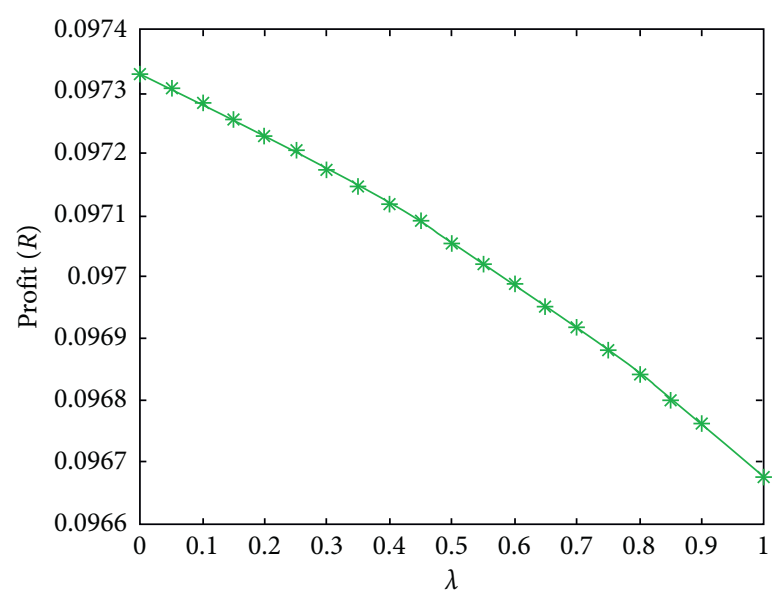

- $-\mathrm{DL}$

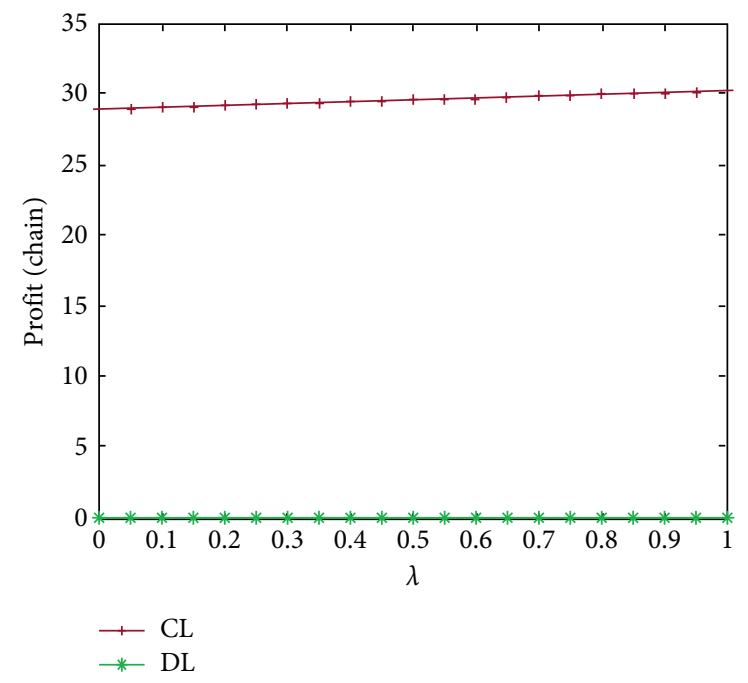

(b)

(c)

FIGURE 2: Effect of regret sensitivity coefficient on supply chain profit. 


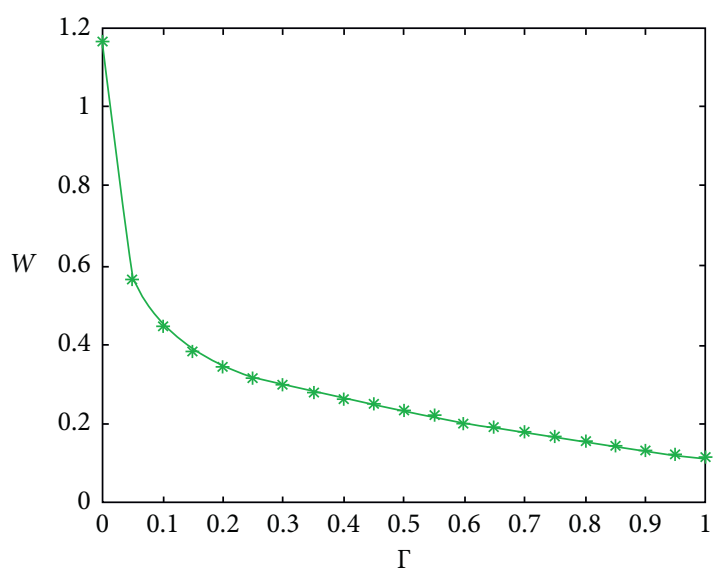

$\rightarrow$ DL

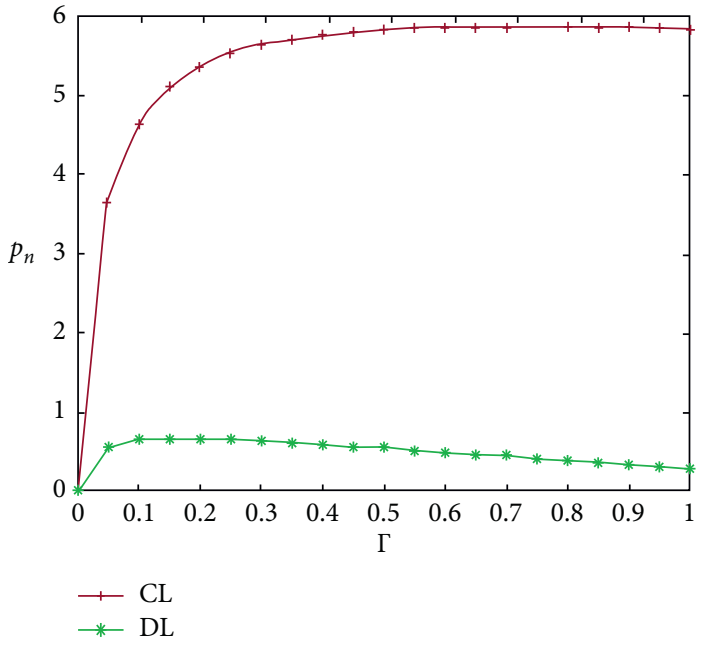

(b)

Figure 3: Effect of consumer heterogeneity on the wholesale and retail prices.

It can be seen from Figure 2 that with the increase in regret sensitivity coefficient, the manufacturer's profit and the retailer's profit both decrease, which indicates that reducing the down jacket price will cause supply chain enterprises to bear more profit risk. Manufacturers need to understand consumers' regret behavior. For consumers with high degree of regret, manufacturers adopt the strategy of "committed advertising" to promise consumers price and quality. Retailers adopt the strategy of "reputation pricing" to make the price of products with reputation higher than that of similar products in the market so as to effectively eliminate the psychological barriers of buyers. The profit of the market leader is the highest, and the decision maker often has the "first-mover advantage."

7.2. Sensitivity Analysis of Consumer Heterogeneity. As different types of consumers have different acceptance of the original price products and discount products, $\gamma$ is used to express the heterogeneity of consumers, and further research on the influence of the heterogeneity of consumers on the price and profitability of the original price and discount products is shown in Figures 3 and 4.

It can be seen from Figure 3 that with the increase in consumer heterogeneity, both wholesale price and retail price of products would decrease. This indicates the greater difference between consumers' acceptance of original price and discount. The higher the market transaction risk is, the lower the price is. Enterprises should understand consumers' different shopping preferences through market research and adopt "committed advertising strategy" to promise consumers the quality and price so as to reduce the uncertainty of consumers' cognition.

As can be seen from Figure 4, the increase in consumer heterogeneity would lead to a decrease in manufacturers' profits and an increase in retailers' profits, which indicates that the difference between the acceptance degree of the original price and discount by the consumers increases the uncertainty of market transaction. Retailers get more profits because they are closer to the consumers and can adjust their prices in real time. The manufacturer adopts the strategy of "differential customization" and the same product designs of multiple styles and colors to meet different types of consumer demand, and the retailer enterprises adopt the strategy of "differential pricing" to carry out precision marketing for different types of consumers.

\subsection{Optimal Results and Comparison of Different Decision} Models. According to the model and parameter setting in this paper, Table 3 can be obtained by comparing the equilibrium results of centralized decision making, decentralized decision making, and profit-sharing mechanism. It can be seen intuitively that the total profit of the supply chain under centralized decision making is higher than that under decentralized decision making, so it is necessary to coordinate the decentralized decision making. After introducing the contract mechanism to coordinate the decentralized decision making, we can see that when the profit-sharing coefficient satisfies $0 \leq \varphi \leq 1$, there are always $\pi_{m}^{\mathrm{CO}}>\pi_{m}^{d}$, $\pi_{r}^{\mathrm{CO}}>\pi_{r}^{d}$, and $\pi^{\mathrm{CO}}>\pi^{d}$. This proves that the design of profitsharing mechanism increases the profits of the manufacturer and the retailer under decentralized decision making, and the overall profit of the supply chain reaches the total profits of the centralized decision-making supply chain. The contract allocation mechanism well coordinates the decentralized supply chain and realizes the "win-win" of manufacturers and retailers in the supply chain. When $0 \leq \varphi \leq 1$, with the increase in $\varphi$, the manufacturer's profit under the profit-sharing mechanism is gradually reduced and the retailer's profit is gradually increased, and the profit after the manufacturer and the retailer distribute according to any proportion is greater than the profit when the two sides do not cooperate. The total profit of the supply chain coordinated by the profit-sharing contract is always greater than the total profit of the supply chain under the 


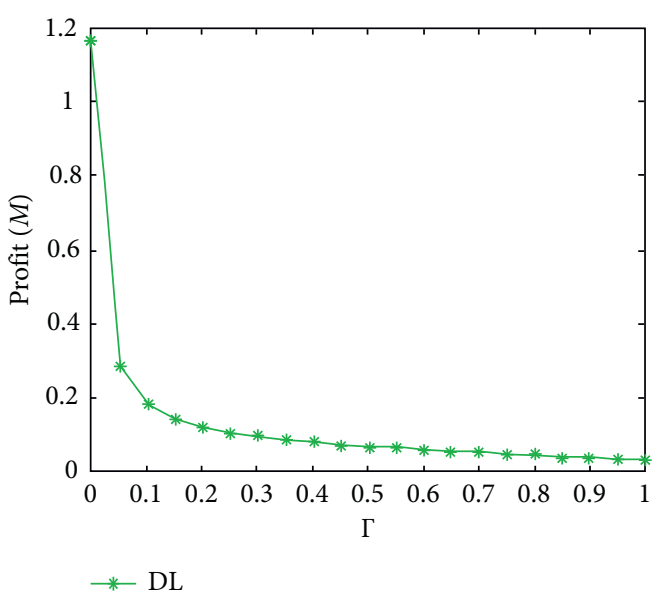

(a)

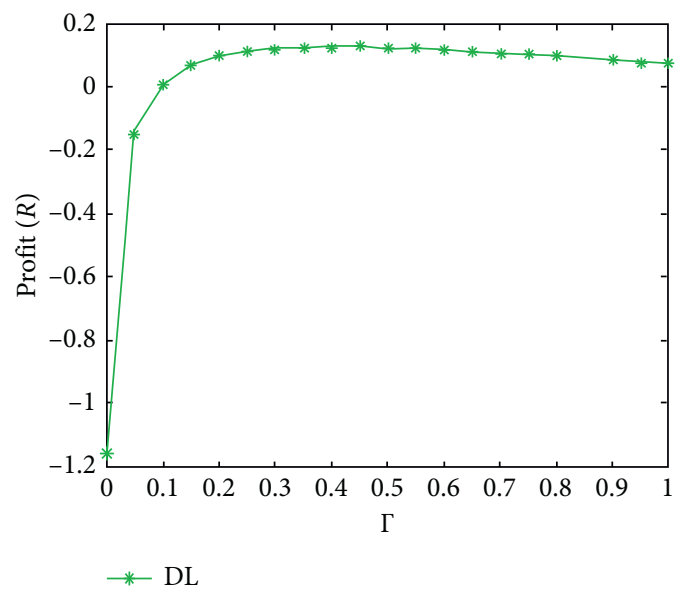

(b)

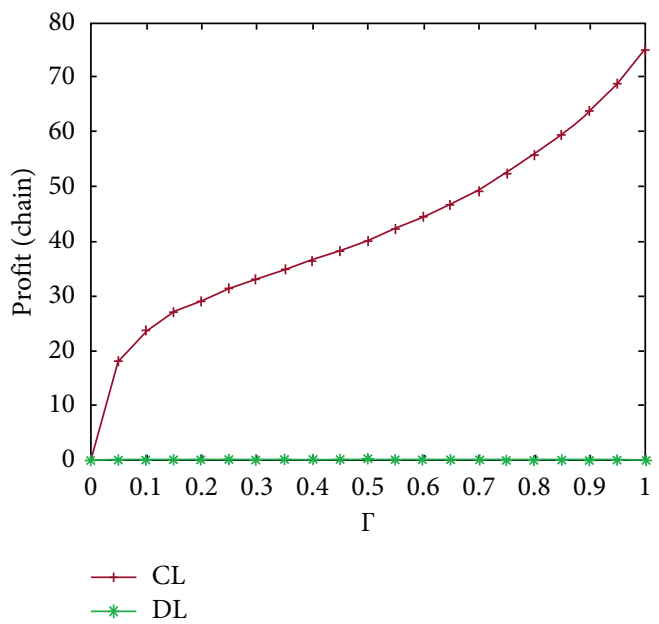

(c)

FIGURE 4: Effort of consumer heterogeneity on supply chain profit.

TABle 3: Profit comparison of members.

\begin{tabular}{|c|c|c|c|c|}
\hline & $0 \leq \varphi \leq 1$ & Manufacturer's profit & Retailer's profit & Total profit \\
\hline Centralized decision & & & & $\pi^{\mathrm{CL} *}=19.3$ \\
\hline Decentralized decision & & $\pi_{m}^{\mathrm{DL} *}=8.5$ & $\pi_{r}^{\mathrm{DL} *}=8.7$ & $\pi^{\mathrm{DL} *}=17.2$ \\
\hline Revenue-sharing contract & $\begin{array}{c}\varphi=0 \\
\varphi=0.3 \\
\varphi=0.8 \\
\varphi=1\end{array}$ & $\begin{array}{c}\pi_{m}^{\mathrm{CO} *}=10.6 \\
\pi_{m}^{\mathrm{CO} *}=10 \\
\pi_{m}^{\mathrm{CO} *}=8.9 \\
\pi_{m}^{\mathrm{CO} *}=8.5\end{array}$ & $\begin{aligned} \pi_{r}^{\mathrm{CO} *}=8.7 \\
\pi_{r}^{\mathrm{CO} *}=9.3 \\
\pi_{r}^{\mathrm{CO} *}=10.4 \\
\pi_{r}^{\mathrm{CO} *}=10.8\end{aligned}$ & $\begin{array}{l}\pi^{\mathrm{CO} *}=19.3 \\
\pi^{\mathrm{CO} *}=19.3 \\
\pi^{\mathrm{CO} *}=19.3 \\
\pi^{\mathrm{CO} *}=19.3\end{array}$ \\
\hline
\end{tabular}

decentralized decision making, which verifies the effectiveness of the coordination mechanism.

\section{Conclusion}

With the fierce market competition, enterprises determine the discount coefficient according to the original price of goods, and "discount promotion" is the most frequent means of promotion in the modern market. There is a new problem about how anticipated regret behavior under the price discount affects the supply chain. In this paper, the demand functions of the original price products and the discount products are described quantitatively based on the consideration of the product price discount and the behavior of anticipated regret. This paper constructs and solves the game model and analyzes the relationship between regret sensitivity coefficient, consumer heterogeneity, price discount, product price, and system profit by theoretical comparison and numerical simulation. The conclusions are as follows. (1) With the increase in regret sensitivity, the original price product has the "price advantage," and the retailer adopts the "skimming pricing strategy." When the heterogeneity of consumers is large (the discount range is small), enterprises adopt "penetration pricing strategy" or 
"discount promotion" to stimulate market demand and avoid this risk. (2) When the heterogeneity of consumers is high, enterprises adopt "penetration pricing" strategy to attract high preference consumers and improve product sales, which will also lead some consumers who prefer discount products to purchase original price products. (3) Price discounts increase the level of consumers' regret perception, and only moderate discounts can improve the profit level of enterprises. Enterprises can adopt "temporary discount strategy" to improve customers' perceived value. In the actual purchase process, consumers have different sensitivity to the anticipated regret of giving up or choosing to purchase. In order to facilitate the comparison of conclusions, the sensitivity of expected regret was set to be the same by referring to relevant literatures. In the future, we will further study the influence of regret sensitivity coefficient on the supply chain game model.

\section{Data Availability}

The data used to support the findings of this study are available from the corresponding author upon request.

\section{Conflicts of Interest}

The authors declare that they have no conflicts of interest.

\section{Acknowledgments}

This study was supported in part by the Doctoral Project of Chongqing Federation of Social Science Circles (grant no. 2018BS71), Humanities and Social Sciences Research General Project of Chongqing Education Commission (grant nos. 18SKGH045 and 18SKGH038), Research Center for Cyber Society Development Problems under Chongqing Municipal Key Research (grant no. 2018skjd06), National Social Science Fund of Chongqing University of Posts and Telecommunications (grant no. 2017KZD10), National Social Science Foundation (grant no. 19BSH122), and Ministry of Education, Humanities and Social Science Projects (grant no. 18XJA630003).

\section{References}

[1] M. Nicola, Z. Alsafi, C. Sohrabi et al., "The socio-economic implications of the coronavirus pandemic (COVID-19): a review," International Journal of Surgery, vol. 78, no. 1, pp. 185-193, 2020.

[2] B. Mellers, A. Schwartz, and I. Ritov, "Emotion-based choice," Journal of Experimental Psychology: General, vol. 128, no. 3, pp. 332-345, 1999.

[3] J. S. Raju, "The effect of price promotions on variability in product category sales," Marketing Science, vol. 11, no. 3, pp. 207-220, 1992.

[4] Y. Xia, "Responding to supplier temporary price discounts in a supply chain through ordering and pricing decisions," International Journal of Production Research, vol. 54, no. 7, pp. 1938-1950, 2016.

[5] G. Cai, Z. G. Zhang, and M. Zhang, "Game theoretical perspectives on dual-channel supply chain competition with price discounts and pricing schemes," International Journal of Production Economics, vol. 117, no. 1, pp. 80-96, 2009.

[6] M. Andrews, X. Luo, Z. Fang, and J. Aspara, "Cause marketing effectiveness and the moderating role of price discounts," Journal of Marketing, vol. 78, no. 6, pp. 120-142, 2014.

[7] D. Gao, N. Wang, Z. He, and T. Jia, "The bullwhip effect in an online retail supply chain: a perspective of price-sensitive demand based on the price discount in E-commerce," IEEE Transactions on Engineering Management, vol. 1, no. 99, pp. 1-15, 2017.

[8] G. P. Chen, X. M. Zhang, and J. Xiao, "Coordination model for cooperative advertising in dual-channel supply chain when online channel implements discount promotion," Journal of Industrial Engineering and Engineering Management, vol. 30, no. 4, pp. 203-209, 2016.

[9] J. Li and X. J. Puyang, "Pricing strategy of e-retailers with discount selling period," Journal of Industrial Engineering and Engineering Management, vol. 31, no. 3, pp. 149-154, 2017.

[10] Y. Wei and L. Xiong, "Supply chain decisions when demand is dependent on promotion, price, and display," Journal of Systems \& Management, vol. 27, no. 3, pp. 571-579, 2018.

[11] X. Wang, W. T. Pan, H. M. Liu et al., "Study on the influence of discount on customer participation product preferences," Journal of Management, vol. 16, no. 8, pp. 1217-1227, 2019.

[12] G. Yang and X. W. Liu, "The selling strategy on dual-channel on-line discounts considering loss preferences," Journal of Systems Engineering, vol. 34, no. 1, pp. 102-115, 2019.

[13] G. Loomes and R. Sugden, "Regret theory: an alternative theory of rational choice under uncertainty," The Economic Journal, vol. 92, no. 368, pp. 805-824, 1982.

[14] J. Nasiry and I. Popescu, "Advance selling when consumers regret," Management Science, vol. 58, no. 6, pp. 1160-1177, 2012.

[15] B. Jiang, C. Narasimhan, Ö. Turut et al., "Anticipated regret and product innovation," Management Science, vol. 63, no. 12, pp. 4308-4323, 2017.

[16] W. Q. Liu and J. J. Zhang, "Research on price discrimination strategy considering consumers' expectations of regret," Chinese Journal of Management Science, vol. 26, no. 5, pp. 1-8, 2018.

[17] J. J. Nie and L. Ding, "The impact of consumer expectations on the competition strategy of service providers," Soft Science, vol. 30, no. 9, pp. 83-89, 2016.

[18] P. Gao, J. G. Du, J. J. Nie et al., "Impact of consumer's anticipated regret on power structure of competitive remanufacturing supply chain," Chinese Journal of Management Science, vol. 25, no. 1, pp. 78-87, 2017.

[19] P. Gao, J. G. Du, J. J. Nie, and Y. M. Lu, "Consumers regret the impact of remanufacturing supply chain operation model," Computer Integrated Manufacturing System, vol. 26, no. 5, pp. 1434-1444, 2020.

[20] H. Khan, A. Daryanto, C. Liu et al., "How anticipated regret influences the effect of economic animosity on consumers' reactions towards a foreign product," International Business Review, vol. 28, no. 2, pp. 405-414, 2019.

[21] T. Zou, B. Zhou, and B. Jiang, "Product-line design in the presence of cohe presence of coned regret," Management Science, vol. 1, no. 1, pp. 1-33, 2020.

[22] A. Örsdemir, E. Kemahlığlu-Ziya, and A. K. Parlaktürk, "Competitive quality choice and remanufacturing," Production and Operations Management, vol. 23, no. 1, pp. 48-64, 2014. 